\title{
Guiding children towards healthy dietary habits based on nutrition education
}

\author{
Li Ping ${ }^{1}$ \\ ${ }^{1}$ Huanghe S\&T University, Zhengzhou, Henan, 450000
}

\begin{abstract}
Cultivation and development of children's healthy diet behaviors is one the major purposes of children's education, and meanwhile it will have far-reaching impact on the behaviors of behaviors. Healthy diet behaviors of children refer to rational selection and intake of food so that the children can ensure enough intake of nutrition that can meet the needs for metabolism and growth. Thus, it is of vital importance to develop healthy diet habits of children. This study interprets the physical qualities of adolescents, analyzes the guiding role and value of nutrition education on the children's healthy diet behaviors, and explores how to give full play to the role of nutrition education to children's healthy diet behaviors.
\end{abstract}

\section{Introduction}

According to surveys by World Health Organization, aside from factors including congenital conditions, geographic conditions and movements, other factors influence the human nutritional balance; in particular, diet behaviors take up $55 \%$ of the total influence. Meanwhile, some psychologists point out that "the period from 3 to 6 years old is the critical period for development of children's healthy diet behaviors". Children's healthy diet behaviors not only influence their metabolism, but help prevent them from chronic diseases, and play an important role in their cognitive development and psychological progress. Previous studies by experts have found that children's healthy diet behaviors play an indispensable role in children's physical, psychological, emotional and intellectual development and prevent them from diseases. Thus, kindergartens should organize more diverse nutrition education activities to increase their awareness of healthy diets, guide children towards healthy dietary habits that will benefit them for a life time and lay a foundation for their future development ${ }^{[1]}$.

\section{Importance of healthy diet behaviors from the perspective of adolescents' and children's physical quality}

As shown in the "2017 Chinese Children Development Report" issued by China Development Research Foundation in 2017, the early development of children in China presents no rosy picture. As Table 1 shows, from 1999 to 2010, the rate of growth retardation among children aged below 5 increased; from the temporal perspective, $16 \%$ of all children in China suffered from growth retardation in 2010, which indicated that healthy development of children was still an issue worthy attention in China. To pay more attention to children's healthy growth is a critical task in China's initiative to develop a harmonious society. From the perspective of children's behaviors, it can be inferred that most children in China still have not developed healthy dietary habits, and thus impeded their healthy development.

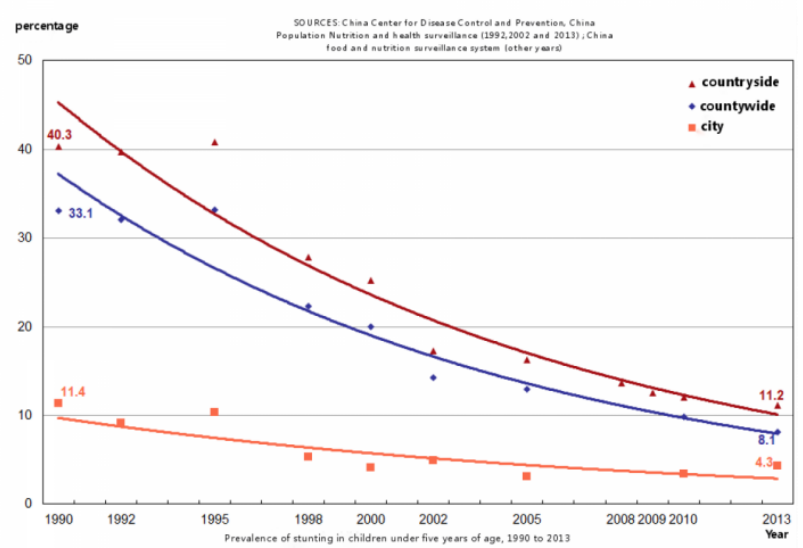

Figure 1. 2017 Chinese Children Development Report the rate of growth retardation of children aged below 5 in $1999-2010$

In $20^{\text {th }}$ May, 2019, China Students Nutrition and Health Development Association, China Nutrition Society, China Dairy Association, Care for Next Generation Committee and other organizations co-held the "adolescents' physical movements and bone health conference" in Zhaoqing, Guangdong, on which the "2018 China Children and Adolescents Nutrition and Health Report" was released. This report pointed out the problems on children's health and nutrition, and proposed 
that "nutrition acquisition is closely correlated to children's bone, intellectual and physical development". On the conference, Mr. Hong Ping from China Student Nutrition and Health Development Association analyzed the conditions of excessive nutrition and malnutrition among children in China, and pinpointed that some chronic disease caused by imbalanced diets such as diabetes and obesity to draw more attention to children's nutrition intake and dietary nutrition ${ }^{[2]}$.

In the conference, Mr. Hong emphasized the importance of healthy dietary habits, pinpointed the dietary habits of children aged below 5 and the physical conditions of children aged between 7 and 10, analyzed the importance of healthy diet for children's future development. In the analysis, according to the changes in the development of height of children aged 7-10 in 2000 - 2014, the average height increase was $3.4 \mathrm{~cm}$ and 2.8 $\mathrm{cm}$, the average weight increase was $5.1 \mathrm{~kg}$ and $3.7 \mathrm{~kg}$. It is obvious that the economic and social development has instrumental impact on children's physical development and improved the height and weight development of children. However, despite the improvement in children's living conditions, some children have developed bad dietary habits and suffered from chronic diseases like obesity, over-nutrition and malnutrition, which need joint efforts from kindergartens, parents and social forces to improve ${ }^{[3]}$.

Studies reviewed above revealed that how to develop healthy dietary habits would be a crucial step in improving the physical conditions of infants, children and adolescents. To improve this problem, kindergarteners, as the guide for children in growth, should undertake their responsibilities and pay attention to children's diet, conduct nutrition education, increase the society's awareness of children's nutrition, encourage children to develop healthy and scientific dietary habits and gain good psychological and physical development.

\section{Analysis of the guiding role and value of nutrition education in development of children's healthy dietary habits}

\section{1 guiding role}

To carry out nutrition education in kindergartens, it is necessary to equip the kindergartens with nutritionists, encourage kindergarteners to learn more nutrition knowledge and impart nutrition knowledge to children to enlighten children on nutrition and increase their awareness of healthy diet. In this process, kindergartens should arrange meals for children under the guidance of professional nutritionists so that children can learn about the benefits of healthy diets through regular lunches, increase the children's interest in healthy meals and prevent them from unhealthy dietary habits, promoting their healthy development as they grow up.

Carrying out nutrition education in kindergartens can integrate nutrition knowledge, healthy dietary habits and rational dietary ideas into the regular life of children. Kindergartens should organize specific nutrition education activities, through which the children can learn about more dietary manners, extend their knowledge of nutritional diet, draw them away from junk food like hamburgers and cola, encourage children to take more diverse food and develop healthy dietary habits so as to give full play to the guiding role of nutrition education in the healthy development of children.

\subsection{Importance}

Given the analyses above, the following two points can be summarized.

First, unhealthy dietary habits prevail among Chinese children. With the quick economic and social development, the factors that influence children's dietary habits are no longer "lack of food" or "shortage of nutrition", but the diverse kinds of "junk food" and "instant food" that they are fond of, their preference for snacks and soft drinks as well as their aversion to their parents' dietary arrangements. Such dietary habits of "replacing staples with unhealthy food" affects the children's intake of nutrition and lead to imbalanced intake of nutrition, causing chronic diseases like obesity, malnutrition and over-nutrition ${ }^{[4]}$.

Secondly, childhood is the critical stage to develop healthy dietary habits and the nutritional intake in this stage will affect the children's growth between 7 and 10 years old or even further. In this stage, children lack selfcontrol or judgement, requiring teachers and parents to provide correct guidance, guide them towards good dietary habits, including not being picky in food, no overeating, no dietary biases, etc., to improve their physical development, protect them from chronic diseases and ensure their healthy development ${ }^{[5]}$.

Given these analyses, carrying out nutrition education in kindergartens can allow children to learn about the importance of healthy diet; diverse and interesting nutrition education activities can increase the children's awareness of healthy dietary habits, encourage them to follow the guidance of teachers and parents, adopt rational dietary habits so that children can develop physical and psychological well-being ${ }^{[6]}$.

\section{How to guide children towards healthy dietary habits through nutrition education}

\section{1 carrying out learning activities on children's dietary nutrition and increasing the students' awareness of healthy diets}

To guide children towards healthy dietary habits through nutrition education, it is advisable to conduct regular learning activities on dietary nutrition through lectures and video presentations to allow the children learn more about healthy dietary habits in an intuitive manner, increase the children's understanding of healthy diets, thus increasing their awareness of dietary health. In practice, it is advisable that kindergartens organize diverse activities including lectures, presentation of videos and animations 
on healthy diets to allow the children to see the regular healthy diets of other children, thus stimulating their motivation to learn from others and guiding them towards healthy dietary habits. Moreover, it is advisable to lead kindergarten children to food processing plants, communities and grocery markets to feel, touch, see and taste the food, increasing their understanding of food. We can also lead children to rural farms to interpret the nutritional components of vegetables and fruits, their health benefits to decrease their aversion to vegetables and avoid the habit of picking food ${ }^{[7]}$.

\subsection{Integrating family education into nutrition education}

To guide children towards healthy dietary habits through nutrition education, it is advisable that kindergarten value family education, encourage parents to develop healthy dietary habits of their children, play a supportive role in kindergartens' nutrition education, so that children can develop good dietary habits. Kindergartens can hold "Family Day" to invite the children's parents to dine with their children, learn more about balanced diets, and create a good environment for children's healthy diets. Kindergartens can also encourage parents to shop food ingredients, prepare lunch or supper, or make dumplings together with their kids, to increase the children's respect for food, reduce their bad habits of picking food, and guide their children towards balanced diets ${ }^{[8]}$. Moreover, kindergartens can organize regular lectures for parents to allow them to know more about the connection between children's bad dietary habits and the family background, so that they can change their dietary habits, set good examples for their kids to develop healthy dietary habits.

\subsection{Designing interesting activities about healthy diets to encourage children to develop good dietary habits}

To guide children towards healthy dietary habits through nutrition education, it is advisable that kindergarten organize diverse nutrition education activities to develop healthy dietary habits unwittingly and correct the mistakes in their cognition of healthy diets. In practice, children can, according to the document of "kindergarten education guidelines (trial)", pursue the goals of "physical health", "good living habits", "knowing basic health preservation". Also, by considering the actual conditions and characters of children in the higher class and lower class, the kindergarten can organize small events like "I am a nutritionist", allowing children to work in groups to learn more about nutrition knowledge, and help children develop good dietary habits ${ }^{[9]}$.

\subsection{Carrying out nutrition education in diverse scenarios to give its guiding role full play}

To guide children towards healthy dietary habits through nutrition education, it is advisable to carry out "random" nutrition education. In regular teaching practice in kindergartens, teachers can design teaching scenarios and activities in light of the educational purposes. For instance, when introducing "A Day of a Squirrel", the teacher can propose the question "what nutritional components do the pine nuts that the little squirrel eat have? Do you know?" to stimulate the kids' curiosity and encourage the kids to learn more about the nutritional value of food, thus helping the kids develop healthy dietary habits ${ }^{[10]}$.

\section{Conclusions}

In summary, nutrition education is an important part of regular education in the kindergarten, and an important step to develop children's healthy dietary habits. How to give the guiding role of nutrition education in developing children's healthy dietary habits is an issue worth researching. Actual education practice in kindergartens reveals that many kids still have bad dietary habits, which will impede their long-term development in the future. Therefore, it is advisable that kindergarten value nutrition education and develop the children's healthy dietary habits, organize regular learning sessions for healthy diets and nutrition, and engage parents in nutrition education to create a favorable environment for nutrition education of children. Kindergartens can organize diverse education activities, such as "healthy food with fun" and "small games" to increase the kids' interest in nutrition, teach them knowledge about healthy diets and thus improve their diets. Moreover, kindergartens can also introduce nutrition education to regular teaching practice, influence the kids' cognition and habits unwittingly, and help them develop healthy and rational dietary habits.

\section{References:}

1. Jin Guozhen. Status quo of nutrition education in kindergartens and solutions - A case study of Kindergarten Q [J]. Journal of Western, 2020(08):113-115.

2. Wang Yanling. Integration - merge - combination: nutrition of children and strategies of health education [J]. Intelligence, 2020(10):167.

3. Tang Lu, Huang Haode, Liu Yumei, et al. Analysis and evaluation of nutrition education of preschool children $[\mathrm{J}]$. Food and Nutrition in China, 2019,25(03):5-8.

4. Li Xiuli. Dietary nutrition for 3-6-year-old children and influencing factors $[\mathrm{J}]$. Think Tank Era, 2018(49):185+187.

5. $\mathrm{Xu}$ Hao, Zhang Qianqian. Status quo and influencing factors for children's parents' knowledge, attitude, behaviors in counties in Chongqing [J]. Journal of Shaanxi Xueqian Normal University, 2018, 34(04):92-95.

6. Zhang Zuoren. Regional development of practice courses of "Little Nutritionists" [J]. Shanghai Research on Education, 2018(04):64-67.

7. Feng Jing. On the development of children's healthy dietary behaviors [J]. Journal of Kaifeng Institute of Education, 2018, 38(03):223-224. 
8. Wang Lianzhen. Progress of nutrition education for preschool children [J]. Chinese Journal of Child Health Care, 2017, 25(04):372-374.

9. Wang Yu, Huang Chengjia. Research on nutrition knowledge, education attitude and behaviors of kindergarten teachers in rural and urban areas in Chongqing [J]. Journal of Chongqing University of Education, 2016, 29(02):118-121+126.

10. Chen Xuwei. Background for implementation of dietary nutrition education for children in America and its lessons for China [J]. Studies in Preschool Education, 2016(03):15-28. 